\title{
Comparative Study between Pentacam and IOL Master in Measuring Anterior Segment Parameters in Eyes of Egyptian Individuals
}

\author{
ALI H. SAAD, M.D.; THANAA HELMY, M.D.; YASSER EL-ZANKALONY, M.D. and \\ MINA SAMEH, M.Sc. \\ The Department of Ophthalmology, Faculty of Medicine, Ain Shams University, Cairo, Egypt
}

\begin{abstract}
Background: Accurate values of anterior segment parameters are important for diagnosing variety of diseases and for cataract surgery, glaucoma, refractive surgery and postoperative follow-up. The true values of Anterior Chamber Depth (ACD), corneal power (K-readings) and White-toWhite (WTW) are essential in calculating the Intraocular Lens power (IOL). The measurement of the ACD and WTW is essential for the success of phakic IOL implantation in patients asking for refractive surgery. This is now possible because of the development of new, accurate diagnostic and surgical tools.
\end{abstract}

Aim of Study: To compare values of anterior segment parameters (ACD, K-reading, WTW) obtained by Pentacam and IOL master to know if there are significant differences in measurement results between both devices or only minimal differences which can be neglected.

Patients and Methods: This comparative cross sectional study included 40 eyes of 22 Egyptian individuals. Evaluation included best corrected visual acuity, slit-lamp evaluation and autorefractometer reading. Imaging by investigative method in the form of IOL master 500 and Pentacam Oculus. All investigations and examinations were done at Kobri El-Kobba military Hospital, Cairo. From January 2018 to August 2018.

Results: IOL master gives statistically significant higher value of K-readings (43.56 $\pm 1.72 \& 45.03 \pm 1.59$ for K1 \& K2 respectively) than Pentacam ( $43.28 \pm 1.73 \& 44.72 \pm 1.58$ for $\mathrm{K} 1$ \& K2 respectively). Low significant difference between both devices in values of ACD (mean difference \pm SD $-0.03 \pm$ 0.10 ). Pentacam measures longer WTW value (mean $12.10 \pm$ 0.45 ) than IOL master (mean $12.00 \pm 0.41$ ).

Conclusion: IOL master gives slightly higher K-reading than Pentacam. Both devices measure ACD accurately and give nearly similar results. IOL master gives reliable WTW estimation but pentacam measurement of WTW by inserting calipers on scheimpflug image may give different values than IOL master.

Key Words: Anterior chamber depth - White-to-White - Kreadings - IOL master - Pentacam.

Correspondence to: Dr. Ali H. Saad, The Department of Ophthalmology, Faculty of Medicine, Ain Shams University, Cairo, Egypt

\section{Introduction}

MEASURING parameters of anterior segment of the eye accurately is important for diagnosing variety of diseases and for cataract surgeries, glaucoma, refractive surgeries and post-operative follow-up. The true values of Anterior Chamber Depth (ACD), corneal power (K-readings), corneal astigmatism and White-to-White (WTW) are essential in calculating the Intraocular Lens (IOL) power, specially with the newer generations of biometric formulas [1]. The measurement of the ACD and WTW is essential for the success of phakic IOL implantation in high refractive error patients asking for refractive surgery. Errors in evaluating these parameters before surgery may result in postoperative unwanted errors of refraction [2]

Different technologies are used in measurement of the structures of the anterior segment. In recent years, technologies used for anterior segment imaging have developed rapidly. New devices based on Scheimpflug imaging, such as the Pentacam and Galilei Dual Scheimpflug Analyzer (GDSA), or high speed anterior segment optical coherence tomography, or partial coherence interferometry based devices as Zeiss IOL Master, or very high frequency ultrasound. These devices provide qualitative and quantitative information about the anterior segment including corneal parameters, ACD, anterior chamber angle and WTW, and they are now being routinely used in ophthalmological practice. They also have the advantage of being noncontact devices and easy to use [3]

Also, accurate anterior segment parameters values are mostly indicated in preoperative evaluation of cataract surgeries. Modern cataract surgery can be considered a form of refractive surgery, 
aiming to improve visual clarity and to provide excellent vision in refractive terms. This is now possible because of the development of new, accurate diagnostic and surgical tools [3].

The cornea is responsible for $2 / 3$ of the total optical power of the eye and hence the accurate assessment of corneal curvature is very important in ophthalmic practice [4]. Different keratometry systems are available for use. Manual keratometer used to measure pre-operative corneal astigmatism but accurate measurement by it requires a learning curve and measured values can differ according to the operator. Automated devices can be used such as autorefractor keratometer, IOL master, three Placido disk based corneal topographers, Scheimpflug camera devices as Pentacam and Sirius [5].

Depth of Anterior Chamber (ACD) is the distance between the anterior surface of the crystalline lens and posterior surface of cornea. The ACD can be measured clinically using different methods. The oldest method is the manual optical pachymeter. IOL Master device then was introduced, which uses a non-laser optical slit method to determine the ACD. Scheimpflug imaging cameras were introduced later, allowing for a photographic scan and analysis of the ACD including the Pentacam and the Galilei [6].

The White-to-White (WTW) corneal diameter is defined by the horizontal distance between the borders of the corneal limbus [7]. Available techniques for the measurement of WTW distance including manual techniques, as surgical calipers, corneal gauges. Also, automated techniques, as ultrasound biomicroscopy, IOL master, anterior segment OCT and Pentacam. Automated measurements provide more precise results than manual techniques [8]

The aim of this study was to compare values of anterior segment parameters (ACD, K-reading, WTW) obtained by Pentacam and IOL master to know if there are significant differences in measurement results between both devices or only minimal differences which can be neglected.

\section{Patients and Methods}

This study was performed on 40 eyes of 22 Egyptian individuals. Subjects included in this study were aged between twenty and forty years, presenting for glass prescription, asking for refractive surgery or coming for just check up. All investigations and examinations were done at Kobri ElKobba Hospital, Cairo during the period of the study from January 2018 to August 2018. The patients signed written consent after they were informed about the nature of the study. Subjects with previous ocular or refractive surgery, ocular trauma, keratoconus patients, uveitis patients or individuals with history of recent contact lens wear, all were excluded from the study. All participants past ocular history and general medical history were checked. All of them were examined for unaided and best corrected visual acuity using Landolt's chart and autorefractometer reading was taken. Slit lamp examination for anterior segment of the eye was done prior to the imaging. All enrolled individuals were imaged by investigative techniques in the form of IOL master 500 and Pentacam oculus HR in the same session and by the same operator.

IOL master 500: Optical biometry by the Zeiss IOL Master was introduced in the United Kingdom in 1999. Its technology is based on laser interferometry with partial coherent light, termed as Partial Coherence Interferometry (PCI) [9]. The device uses the principle of PCI to measure the axial length of the eye. While uses a slit-beam photographic technique for ACD measurements [10]. For keratometry measurement, six light spots are projected hexagonally on the cornea [1]. The device records the reflection of these images measuring the separation of the opposite pairs of light spots and calculating the corneal radii and toroidal surface curvature. The mean of the taken measurements is considered the corneal power [11]. The displayed $\mathrm{K} 1$ and $\mathrm{K} 2$ represent the average keratometry values at two major perpendicular meridians [12] For ACD measurement, the IOL Master directs a slit beam of light $0.7 \mathrm{~mm}$ wide through the anterior segment at an angle of $38^{\circ}$ to the visual axis. The internal software measures the distance between anterior pole of the cornea and the anterior surface of the lens to calculate the ACD [13]. The device takes five ACD measurements in rapid succession; the mean of these readings are taken as the ACD value [14]. For WTW measurement, a digital greyscale photograph of the anterior surface of the eye is taken after focusing on the iris. The limbus is then detected automatically and the WTW distance is measured [15]

Pentacam oculus: The Pentacam obtains images of the anterior segment by a rotating Scheimpflug blue Light Emitting Diode (LED) with a wavelength of $475 \mathrm{~nm}$. It acquires 50 images in a duration of approximately two seconds. It extracts about 2,760 true elevation points from the obtained images which in turn generates 138,000 true elevation points for the both front and back corneal surfaces 
and from limbus to limbus, including the central part of the cornea [16]. There for, it calculates kreadings of the cornea. The Pentacam HR calculates ACD from the corneal endothelial layer along a line from the apex of the cornea to the anterior surface of the lens [17]. Horizontal WTW was measured in this study by manual placement of callipers on the Scheimpflug image of the horizontal plane of the examined eye; callipers are placed on the corneo-scleral junction then a line is automatically drawn between the two points Fig. (1). The length of this line represents the WTW value [18]

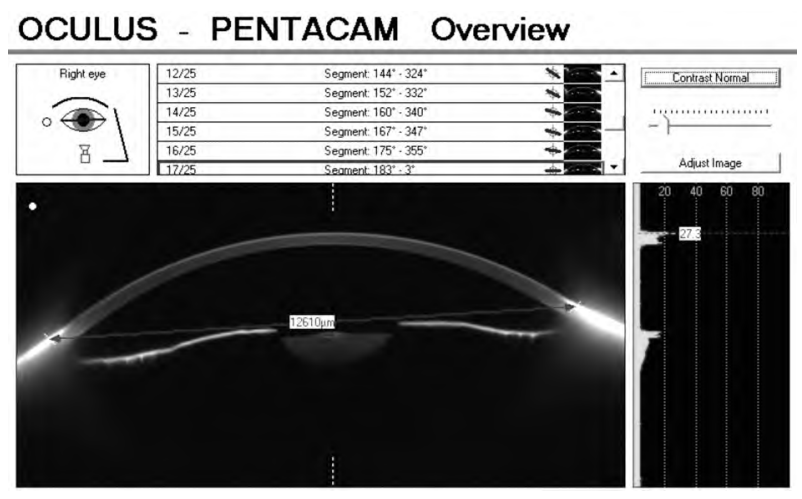

Fig. (1): Manual placing of calipers on the limbus for WTW measurement.

\section{Statistical analysis:}

The collected data from both pentacam \& IOL master were revised, coded, tabulated in Microsoft Excel sheet including age, sex, $\mathrm{K} 1-\mathrm{K} 2$ readings, ACD, WTW values. The collected data were arranged for use in SPSS package. Data were expressed as mean \pm Standard Deviation (SD). Throughout the statistical analysis, the results were considered statistically significant when the significance level or $p$-value $\leq 0.05$.

\section{Results}

This is a cross sectional comparative study carried out on 40 eyes of 22 Egyptian individuals underwent phacoemulsification and IOL implantation surgery. There were 4 males and 18 females shared in the study. Their age was ranging from 21 years to 38 years with an average of $28.80 \pm 5.92$ years. Table (1) shows the K1 values obtained by pentacam ranged from 38.8 to $46.36 \mathrm{D}$ with mean $43.28 \pm 1.73 \mathrm{D}$. While by IOL master, K1 ranged from 39.29 to $46.36 \mathrm{D}$ with mean $43.56 \pm 1.72 \mathrm{D}$. The K2 values obtained by pentacam ranged from 41.3 to $47.5 \mathrm{D}$ with mean $44.72 \pm 1.58 \mathrm{D}$. While by IOL master, K2 ranged from 41.46 to $47.74 \mathrm{D}$ with mean $45.03 \pm 1.59 \mathrm{D}$. From (Table 1) there is high statistically significant difference between pentacam and IOL master in both $\mathrm{K} 1 \& \mathrm{~K} 2$ with $p$-value $<0.01$.

Table (1): Comparison between K-reading values obtained by pentacam and IOL master.

\begin{tabular}{|c|c|c|c|c|c|c|}
\hline \multirow{2}{*}{ K-reading } & \multirow{2}{*}{$\begin{array}{c}\text { Pentacam } \\
\text { HR }\end{array}$} & \multirow{2}{*}{$\begin{array}{l}\text { IOL } \\
\text { master }\end{array}$} & \multirow{2}{*}{$\begin{array}{c}\text { Mean } \\
\text { difference } \\
\pm \mathrm{SD}\end{array}$} & \multicolumn{3}{|c|}{ Paired $t$-test } \\
\hline & & & & $t$ & $\underset{\text { value }}{p^{-}}$ & Sig. \\
\hline \multicolumn{7}{|l|}{ K1: } \\
\hline - Mean \pm SD & $43.28 \pm 1.73$ & $43.56 \pm 1.72$ & $0.28 \pm 0.13$ & -14.053 & 0.000 & HS \\
\hline - Range & $38.8-46.1$ & $39.29-46.36$ & & & & \\
\hline \multicolumn{7}{|l|}{$K 2$ : } \\
\hline - Mean \pm SD & $44.72 \pm 1.58$ & $45.03 \pm 1.59$ & $0.31 \pm 0.19$ & -10.154 & 0.000 & HS \\
\hline - Range & $41.3-47.5$ & $41.46-47.74$ & & & & \\
\hline
\end{tabular}

Table (2) shows that ACD value by Pentacam ranged from 3.00 to $4.06 \mathrm{~mm}$ with mean $3.53 \pm 0.25$ $\mathrm{mm}$. While by IOL master, ACD ranged from 2.97 to $4.11 \mathrm{~mm}$ with mean $3.50 \pm 0.25 \mathrm{~mm}$. There is no significant difference between pentacam and IOL master in ACD value with $p$-value $>0.05$. IOL master measures higher K-reading value than Pentacam.

Table (2): Comparison between ACD by Pentacam \& IOL master.

\begin{tabular}{llllll}
\hline \multirow{2}{*}{ ACD } & Pentacam & \multicolumn{1}{c}{$\begin{array}{c}\text { IOL } \\
\text { master }\end{array}$} & $\begin{array}{c}\text { Mean } \\
\text { difference } \\
\pm \mathrm{SD}\end{array}$ & \multicolumn{2}{c}{ Paired $t$-test } \\
\cline { 5 - 6 } & & & $t$ & $p$-value Sig. \\
\hline Mean $\pm \mathrm{SD}$ & $3.53 \pm 0.25$ & $3.50 \pm 0.25$ & $-0.03 \pm 0.10$ & 1.814 & $0.077 \mathrm{NS}$ \\
Range & $3-4.06$ & $2.97 \pm 4.11$ & & & \\
\end{tabular}

$p$-value $>0.05$ : Non significant.

$p$-value $<0.05$ : Significant.

$p$-value $<0.01$ : Highly significant

Table (3) shows that By pentacam, WTW ranged from 11.2-13.09mm with mean $12.10 \pm$ $0.45 \mathrm{~mm}$. While by IOL master, WTW ranged from $11.3-12.9 \mathrm{~mm}$ with mean $12.00 \pm 0.41 \mathrm{~mm}$. Pentacam gives significant different WTW value than IOL master with $p$-value $<0.05$.

Table (3): Comparison between WTW by Pentacam \& IOL master.

\begin{tabular}{lccccc}
\hline \multirow{2}{*}{ WTW } & Pentacam & $\begin{array}{c}\text { IOL } \\
\text { master }\end{array}$ & $\begin{array}{c}\text { Mean } \\
\text { difference } \\
\pm \mathrm{SD}\end{array}$ & \multicolumn{2}{c}{ Paired $t$-test } \\
\cline { 5 - 6 } & & & \multicolumn{1}{c}{$p$-value Sig. } \\
\hline Mean $\pm \mathrm{SD}$ & $12.10 \pm 0.45$ & $12.00 \pm 0.41$ & $-0.10 \pm 0.27$ & 2.349 & $\mathbf{0 . 0 2 4} \mathrm{S}$ \\
Range & $11.2 \pm 13.09$ & $11.3 \pm 12.9$ & & & \\
\hline
\end{tabular}

$p$-value $>0.05$ : Non significant

$p$-value $<0.05$ : Significant.

$p$-value $<0.01$ : Highly significant 


\section{Discussion}

Accurate assessment and measuring parameters of the anterior segment of the eye is very important in ophthalmology practice. New imaging techniques were introduced within last years and more accurate technologies were added to already present devices to improve their accuracy and performance. IOL master is used in recent years for assessment of eyes specially for preoperative IOL power calculation formulas. Pentacam scheimpflug imaging then was introduced for more detailed images of anterior segment of the eye and a full map of corneal topography. This study was done to compare between the values of anterior segment parameters (K-readings, ACD, WTW) obtained by Pentacam and IOL master. A total of 40 eyes of 22 Egyptian individuals included in this study and they were examined by both Pentacam and IOL master.

In our study, the mean K-readings by Pentacam, $\mathrm{K} 1 \& \mathrm{~K} 2$ are $43.28 \pm 1.73 \& 44.72 \pm 1.58$ respectively. The mean K-readings by IOL master $500, \mathrm{~K} 1$ $\& \mathrm{~K} 2$ are $43.56 \pm 1.72 \& 45.03 \pm 1.59$ respectively. Our study shows statistically significant difference between mean K-reading by Pentacam and IOL master $500(p<0.01)$. This results agreed with Dong et al., [19] in 2015 which found significant difference between both devices in flat K1 and steep K2 values. His study was done on Chinese group. Also, Woodmass et al., [20] in 2009 and Elbaz et al., [21] in 2007 studies found that Pentacam mean $\mathrm{K}$ value is lower than that of IOL master. On the reverse Laursen et al., [22] in 2016 study compared keratometry by different 5 devices. Minimal differences was found between pentacam \& IOL master in mean K-reading which in general was not significant. The study was done on higher age group (39 to 88 years). This study agreed with our study that IOL master gives relatively higher Kreading than other methods including Pentacam oculus.

Our study shows that mean ACD by Pentacam is $3.53 \pm 0.25 \mathrm{~mm}$. While mean ACD by IOL master is $3.50 \pm 0.25 \mathrm{~mm}$. Mean difference between both devices is $-0.03 \pm 0.10$. The study shows minimal insignificant difference between both devices $(p>0.05)$. This result agreed with results of Shajari et al., [23] in 2016, the study found that no statistically significant difference between Pentacam HR and IOL master in ACD value in healthy unoperated eyes. Also Domínguez-vicent et al., [15] in 2015 and Muzyka-Wozniak et al., in 2018 [24] studies agreed that there is minimal insignificant difference between both devices in ACD value. Fernandez-
Vigo et al., [25] in 2016 study done on 1006 eyes of Caucasian individuals, showed excellent agreement between Pentacam and IOL master in ACD measurements. On the reverse, Utine et al., [26] in 2009 found that IOL master ACD values were $0.11 \mathrm{~mm}$ less than Pentacam ACD values. The mean difference between IOL master and Pentacam measurements was $3.16 \%$ of the mean ACD calculated across all measurements but this difference is too small to create significant difference in refractive outcome.

Our study results mean WTW value by pentacam was $12.10 \pm 0.45 \mathrm{~mm}$ while that of IOL master was $12.00 \pm 0.41 \mathrm{~mm}$. Significant difference was found in WTW by both devices ( $p$-value 0.024 ). The Pentacam gives longer WTW than IOL master (mean difference $-0.10 \pm 0.27 \mathrm{~mm}$ ). Shajari et al., [23] in 2016 found higher value of WTW by IOL master (mean $12.0 \pm 0.3 \mathrm{~mm}$ ) than that of Pentacam (mean $11.8 \pm 0.4 \mathrm{~mm}$ ). The study done using Pentacam HR (Oculus, Germany), the version which include iris camera that can measure WTW automatically so, it's operator independent measure of WTW on the contrary to our study in which WTW was measured subjectively by manual insertion of a scale on the general scheimpflug image of horizontal view. Domínguez-Vicent et al., [15] in 2015 found low significant difference in WTW by Pentacam HR and IOL master (mean difference $0.07 \pm$ $0.10 \mathrm{~mm}$ ). The study said that both devices can be used interchangeably to each other to measure WTW as IOLs are produced to the nearest $0.50 \mathrm{~mm}$. Elkateb, Swelem [18] study in 2016 done in Egypt compared WTW by pentacam and IOL master and found that mean WTW by pentacam (mean $11.93 \pm$ $0.43 \mathrm{~mm}$ ) is higher than WTW by IOL master (mean $11.66 \pm 0.27 \mathrm{~mm}$ ). It was done by the same method used in our study for WTW by pentacam which is manual placing of two calipers on the scheimpflug image of the pentacam. The study said that there is significant difference between both devices so, they can't be used interchangeable to each other for WTW measurement.

\section{Conclusion:}

We concluded from this study that both Pentacam oculus and IOL master 500 are excellent noncontact devices for assessment and accurate measurement of anterior segment parameters of the eye. IOL master gives slightly higher K-reading than Pentacam. This difference may be statistically significant but we needs to know by further studies if it's practically significant or not. Both devices measure ACD accurately and give nearly similar results so, both of them can be used interchangeable to each other to measure ACD taking into account 
to be from corneal epithelium to anterior lens capsule. IOL master gives reliable WTW estimation but pentacam manual measurement of WTW by inserting calipers on scheimpflug image may give different results as its subjective operator dependant to some extent.

\section{References}

1- LOPEZ De La FUENTE C., SANCHEZ-CANO A., SEGURA F. and PINILLA I.: Comparison of Anterior Segment Measurements Obtained by Three Different Devices in Healthy Eyes. Bio. Med. Res. Int., 2014: 1-8, 2014.

2- UÇAKHAN Ö.Ö., AKBEL V., B1Y1KL1 Z. and KANPOLAT A.: Comparison of Corneal Curvature and Anterior Chamber Depth Measurements Using the Manual Keratometer, Lenstar LS 900 and the Pentacam. Middle East Afr. J. Ophthalmol., 20 (3): 201-6, 2013.

3- ADEMOLA-POPOOLA D.S., NZEH D.A., SAKA S.E., OLOKOBA L.B. and OBAJOLOWO T.S. : Comparison of ocular biometry measurements by applanation and immersion A-scan techniques. J. Curr. Ophthalmol., Sep., 27 (3-4): 110-4, 2015.

4- HAMER C., BUCKHURST H., PURSLOW C., SHUM G., HABIB N. and BUCKHURST P.: Comparison of reliability and repeatability of corneal curvature assessment with six keratometers, 99 (6): 583-9, 2016.

5- PARK J.H., KANG S.Y., KIM H.M. and SONG J.S.: Differences in corneal astigmatism between partial coherence interferometry biometry and automated keratometry and relation to topographic pattern. J. Cataract. Refract. Surg., Sep., 37 (9): 1694-8, 2011.

6- HOFFER K.J. and SAVINI G.: Anterior chamber depth studies. J. Cataract. Refract. Surg., Sep., 41 (9): 1898904, 2015.

7- FERRER-BLASCO T., ESTEVE-TABOADA J.J., MARTÍNEZ-ALBERT N., ALFONSO J.F. and MONTÉSMICÓ R.: Agreement of white-to-white measurements with the IOLMaster 700, Atlas 9000, and Sirius systems. Expert Rev. Med. Devices, Jun. 3, 15 (6): 453-9, 2018.

8- BAUMEISTER M., TERZI E., EKICI Y. and KOHNEN T.: Comparison of manual and automated methods to determine horizontal corneal diameter. J. Cataract. Refract. Surg., Feb., 30 (2): 374-80, 2004.

9- OLSEN T.: Improved accuracy of intraocular lens power calculation with the Zeiss IOLMaster. Acta Ophthalmol. Scand., Oct. 5, 85 (1): 84-7, 2006.

10- NAKAKURA S., MORI E., NAGATOMI N., TABUCHI H. and KIUCHI Y.: Comparison of anterior chamber depth measurements by 3-dimensional optical coherence tomography, partial coherence interferometry biometry, Scheimpflug rotating camera imaging, and ultrasound biomicroscopy. J. Cataract. Refract. Surg., Jul., 38 (7): 1207 13, 2012.

11-KARUNARATNE N.: Comparison of the Pentacam equivalent keratometry reading and IOL Master keratometry measurement in intraocular lens power calculations: Pentacam keratometry in lens calculation. Clin. Experiment. Ophthalmol., Dec., 41 (9): 825-34, 2013.
12-MEHRAVARAN S., ASGARI S., BIGDELI S., SHAHNAZI A. and HASHEMI H.: Keratometry with five different techniques: A study of device repeatability and interdevice agreement. Int. Ophthalmol., Aug., 34 (4): 869 $75,2014$.

13 - SANTODOMINGO-RUBIDO J.: A new non-contact optical device for ocular biometry. Br. J. Ophthalmol., Apr. 1, 86 (4): 458-62, 2002.

14- BUENO-GIMENO I., ESPAÑA-GREGORI E., GENÉSAMPEDRO A., LANZAGORTA-ARESTI A. and DUALDE-BELTRÁN C.: Anterior chamber depth measurement in teenagers. Comparison of two techniques. J. Optom., Jul., 6 (3): 161-6, 2013.

15-DOMÍNGUEZ-VICENT A., PÉREZ-VIVES C., FERRERBLASCO T., ALBARRÁN-DIEGO C. and MONTÉSMICÓ R.: Interchangeability among five devices that measure anterior eye distances: Agreement among anterior eye measurements. Clin. Exp. Optom., May, 98 (3): 254 62, 2015.

16- JAIN R. and GREWAL S.: Pentacam: Principle and Clinical Applications. Dada T, Singh K, Spaeth GL, editors. Curr. J. Glaucoma Pract., DVD, May, 20-32, 2009.

17- McALINDEN C., KHADKA J. and PESUDOVS K.: A Comprehensive Evaluation of the Precision (Repeatability and Reproducibility) of the Oculus Pentacam HR. Investig. Opthalmology Vis. Sci., Sep. 28, 52 (10): 773 1, 2011.

18- ELKATEB M. and SWELEM H.: Measurement of Whiteto-White Distance Using Pentacam Scheimpflug Imaging versus IOLMaster. Egypt J. Cataract. Refract. Surg., 22 (1): 10, 2016.

19- DONG J., TANG M., ZHANG Y., JIA Y., ZHANG H., JIA Z., et al.: Comparison of Anterior Segment Biometric Measurements between Pentacam HR and IOLMaster in Normal and High Myopic Eyes. Bhattacharya S, editor. PLOS ONE, Nov. 17, 10 (11): e0143110, 2015.

20- WOODMASS J. and ROCHA G.: A comparison of Scheimpflug imaging simulated and Holladay equivalent keratometry values with partial coherence interferometry keratometry measurements in phakic eyes. Can. J. Ophthalmol., 44 (6): 700-4, 2009.

21- ELBAZ U., BARKANA Y., GERBER Y., AVNI I. and ZADOK D.: Comparison of Different Techniques of Anterior Chamber Depth and Keratometric Measurements. Am. J. Ophthalmol., Jan., 143 (1): 48-53, 2007.

22- LAURSEN J.V.N., JEPPESEN P. and OLSEN T.: Precision of 5 different keratometry devices. Int. Ophthalmol., Feb., 36 (1): 17-20, 2016.

23- SHAJARI M., LEHMANN U.C. and KOHNEN T.: Comparison of Corneal Diameter and Anterior Chamber Depth Measurements Using 4 Different Devices: Cornea, Jun. 35 (6): 838-42, 2016.

24- MUZYKA-WOZNIAK M. and OLESZKO A.: Comparison of anterior segment parameters and axial length measurements performed on a Scheimpflug device with biometry function and a reference optical biometer. Int. Ophthalmol., Apr., 39 (5): 1115-22, 2018.

25- FERNÁNDEZ-VIGO J.I., FERNÁNDEZ-VIGO J.Á., MACARRO-MERINO A., FERNÁNDEZ-PÉREZ C., 
MARTÍNEZ-De-La-Casa J.M. and GARCÍA-FEIJOÓ J.: Determinants of anterior chamber depth in a large Caucasian population and agreement between intra-ocular lens Master and Pentacam measurements of this variable. Acta Ophthalmol. (Copenh), Mar., 94 (2): e150-5, 2016.
26- UTINE C.A., ALTIN F., CAKIR H. and PERENTE I.: Comparison of anterior chamber depth measurements taken with the Pentacam, Orbscan IIz and IOLMaster in myopic and emmetropic eyes. Acta Ophthalmol. (Copenh), Jun., 87 (4): 386-91, 2009.

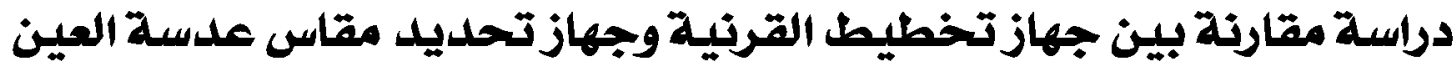

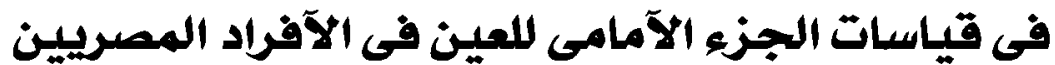

\author{
القياس الدقيق لقيم الجزء الآمامى اللعين هام جداً لتشخيص العديد من آمراض العين العين والتخطيط للعمليات الجراحية والمتابعة بعد الجراحة.

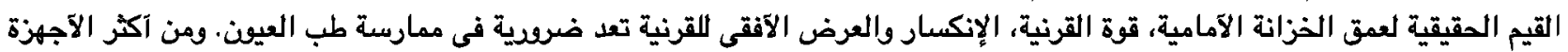

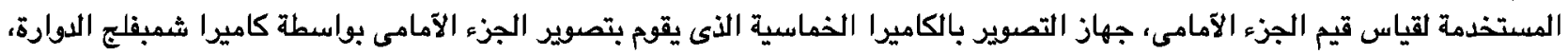 \\ وجهاز تصديد مقاس عدسة العين الذى يعتمد على تكنلوجيا التداخل الجزئى لآثبعة الليزد. \\ في هذه الدراسة، قمنا بالمقارنة بين قيم القطاع الآمامى (قوة القرنية، العرض الآفقى، عمق الخرانة الآمامية) التى حصلنا عليها بإستخدام

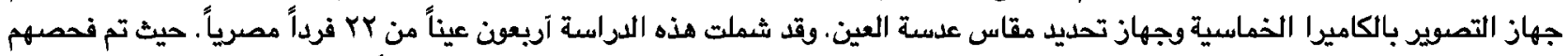

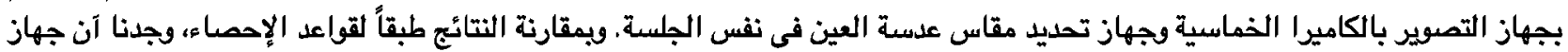

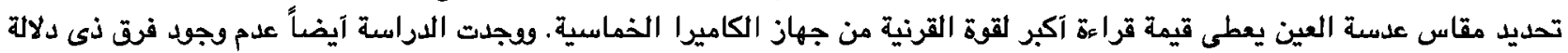

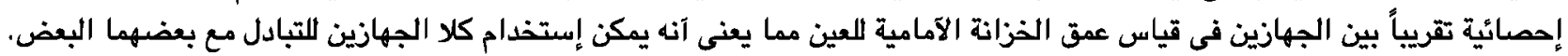

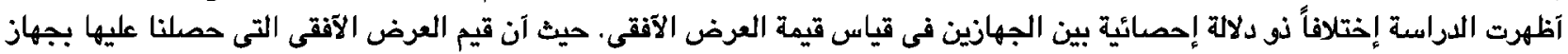

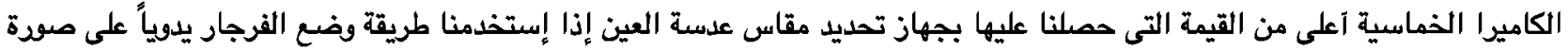 \\ شيمبلج العين المكونة بواسطة جهاز الكاميرا الخماسية.
}

